\title{
A STUDY ON CUSTOMER PERCEPTION AND ATTITUDE TOWARDS 3D VIRTUAL REALITY SHOPPING
}

\author{
Dr. Anand Byram ${ }^{1}$ \\ ${ }^{1}$ Assistant professor in Management, Department of Management, Pondicherry University Karaikal campus, Karaikal -609605- \\ Pondicherry- India
}

\begin{abstract}
An innovative technology application that creates textures of real store shopping experience may generate a rapid momentum in the e-retailing sector. In virtual reality (VR) stores consumers can not only virtually walk anywhere, but they can also interact with the virtual reality store by, right, left, up and down and looking around thereby viewing the shop. There is a comparison difference between existing in user boundaries and Computer-generated systems in 3D environment. creating a simulated artificial world, the computer virtually makes sensory feelings as much as possible, like hearing, vision, touch, even smell. The virtual reality web store could redefine the experience of online shopping and allows in creating an immersive experience that renovate the physical shopping voyage, that from home or anywhere that customers desire. Virtual Reality in Retailing is an innovative proposal that helps the customer to look around the store with a complete 360-degree view along with the controller that helps in the purchase. perceived entertaining and fun that felt by the shoppers to the extent to which online shopping they do. Better informational base helps the consumers to make more informed decisions that make them increase their satisfaction in the online shopping process perceived ease of use could implicit as the degree to which the online shopping customer have faith in that shopping will be free. the effect of the price perception and found impact of price perceptions on behavioralintention. privacy is a conscious effort of e-retailor in dealing with customer data and information.
\end{abstract}

Keyword: virtual reality, e-commerce, v -commerce, eretailing, perception, attitude, customer, shopping

\section{Introduction}

An innovative technology application that creates textures of real store shopping experience may generate a rapid momentum in the e-retailing sector. In a culture where the physical shop is under pressure and online shopping is increasing, the use of Virtual Reality seems a logical step. In virtual reality (VR) stores consumers can not only virtually walk anywhere, but they can also interact with the virtual reality store by, right, left, up and down and looking around thereby viewing the shop as if they are footing in the middle of it. Introduction of a theoretically proposed and empirically established a conceptual model that identifies the significant factors that may reshape the service quality of future virtual reality shopping environments. A great deal of existing offline and online hedonic and utilitarian motive functions can be technically redefined and may predict behavioural intentions. This proposed conceptual model helps in framing different strategies for crafting a store atmosphere that gives a unique shopping experience. This approach offers a distinctive vision into workable marketing strategies to online merchants for developing customer professed virtual reality and superficial emotional online shopping environment.

The experience with the new technology environment, usage, and perceived outcome is positively related (Agarwal and Prasad (1999). The interactivity of the web store environment makes high customer involvement, so the purpose of including constructs from the uses and gratification theory to enhance perceptivity of customer attitude towards $3 \mathrm{D}$ web store as a medium of interactivity of customers intentionally chooses to satisfy their needs. The observed reason for the shopping experience is that there might be a link between the satisfaction and future behavioural intentions created by an environment that influences emotions

This research, proposing a conceptual model with constructs combined from the Uses and Gratification theory and the Technology Acceptance Models attempted in investigating the empirical pieces of evidence of attitude towards innovative virtual shopping environment. The online marketers should go beyond from normal business models of two-dimensional store platforms to three-dimensional virtual reality web stores for creating a potential satisfied user and repeat purchasers.

\section{Virtual Reality}

Virtual Reality is an emerging technology where a computer creates a cyberspace virtual setting. It features a display in front of our eyes. The display streams data, images and other information in front of the wearer's eye(s). Certain HMDs such as Oculus Rift or HTC Vivo have displays over both of their users' eyes. There is a comparison difference between existing in user boundaries and Computer-generated systems in $3 \mathrm{D}$ environment. creating a simulated artificial world, the computer virtually makes sensory feelings as much as possible, like hearing, vision, touch, even smell. The limitations of such simulated virtual reality are content availability and cheap computing power.

Virtual Reality is rapidly becoming popular to the gamers, 3D artists, estate agents' architects, real, teachers and students and 
astronauts. Virtual Reality becoming popular because it taking us from the real world and carry you to a different imaginary world, rather it creates a development to the real world with a variety of thrilling virtual substance, in it, a person feels the real environment is recreated by a computer-generated appealing.

The Virtual Reality precisely makes it promising to experience everything, wherever at any time, one of the predominant immersive forms of reality- technology that persuades the human brain. Head-Mounted Display devices that are operated with earphones and hand controllers give completely immersive experience. In case of virtual-reality experience, a realistic three-dimensional image of the simulated background is produced by a combination of interactive software and hardware that is offered to the user in a way that it seems as real surroundings in which the user can interact perceptually, as actual or physical manner.

Virtual Reality applications invention and consumer demand to it embark on the real spark at in progressing manner. By 2025 attractive Virtual Reality applications will experience commonplace, if it made true sense, as these technologies' innovations demonstrate incredible potential showing virtual reality experiences created employing some key elements.

Virtual World- A virtual world can be considered as a threedimensional atmosphere that is common, though not essentially, is realized through a medium that having portraying and display images where the user may act together with this environment and generate a real-life feeling like part of the interface. In the virtual world, images make illusions and are receptive, these variations in motion and relations are imitations and those will be experienced as same as in the physical world.

The key component behind the virtual-reality arrangement includes a personal computer, console or a smartphone. For Virtual Reality experience, the Personal Computer provides virtual reality content inside the virtual reality headset for the user. To command the interactive three- dimensional environment, considerable computing power is necessary. These Personal Computers, consoles or smartphones works as an engine that power the content being created.

In Commercial usage, the virtual reality already is used in the arena of aviation training. Beginning with flying the commercial aeroplanes out of the busy airport to train the aspiring pilots without unsafe night flight training with night vision, the virtual reality simulations can be provided as a significant method. Steering commercial flights require great responsibility due to the involvement of several hundred passengers on any certain flight.

Virtual Reality in Retailing is an innovative proposal that helps the customer to look around the store with a complete 360-degree view along with the controller that helps in the purchase.

\section{Virtual Reality web store shopping}

As a contemporary integrated marketing strategy, virtual reality technology is using by some of the online sellers. For creating a memorable buying experience, virtual reality is dependable as the content is praised as one of the motivating forces behind lead generation. This momentum will exist a long way in cementing virtual reality in the minds of customers who think about it, that more appealing, reading a product narrative of a dress, virtually changing in different colours and with different accessories

The virtual reality web store could redefine the experience of online shopping and allows in creating an immersive experience that renovate the physical shopping voyage, that from home or anywhere that customers desire. This technology has the potential to transform whole the way of shopping, and online sellers needs to begin preparation for the virtual reality revolution.

The benefit of virtual reality in businesses in different ways, virtual reality can generate well loaded, immersive and memorable customer experience. This technology is capable of doing wonders in conversion rate. Virtual Reality web store is an experience, which enables 360- degree product views.

The virtual reality retail industry seems to be in the nascent phase, with a large player like Oculus, Samsung and is striving to boost customer interests. Virtual Reality and AR are trending unlike previously that ever-increasing numbers of headsets purchased by consumers, and the term Virtual commerce been now created for future events. VR is used by companies such as North face, Alibaba and Lowe to increase their brand sale. The ultimate goal is to form a virtual store for customers where they can select and purchase a product.

Virtual Reality in retailing is projected to decrease marketing cost, lessen product return and offer efficient analytic and the data. Retailers have started to look for Virtual Reality because of its sci-fi feature that creates human interests

V-commerce though growing seems to already make an effect. Irrespective of whether the virtual reality would take a fast pace or not, the companies might be prepared for accepting the v-commerce and plan to provide their customers what they wish.

Key challenges include uncomfortable Virtual Reality headsets and required hardware, as well as the excessive price. But a positive sign, the HTC, Google, Samsung and Apple are working on reasonably priced separate headsets. Virtual Reality started making its space in the e-retail sector due to the steady rise in customer favorability for the advancement in technology.
ISSN (Print): 2204-0595 ISSN (Online): 2203-1731 
This customer behavior research is supporting the fact that there is a pace in which big retailers are moving forward towards this technology for reaping the benefits of being an early adopter. E- Bay, IKEA and Shopify are already made a huge investment for VR technology.

\section{The objective of the study:}

The present study focusses on the following objective To develop a model for perception towards Virtual reality web store

\section{Literature Review and construct developed}

Due to the increasing prominence of e-retailing, interest among researchers and practitioners has been increased towards consumer perception and adoption. Many researchers have tried to theorize online shopping adoption in terms of social psychology and information system perspectives to explore various determinants. These studies have contributed to the knowledge of online shopping behavior, but they failed to provide a comprehensive view by integrating all these diverse approaches.

The claim of stimulus - organism - response theory of model is to normally setups empirically tested that online affects the Performance of online shoppers such as purchase intentions (Babin \& Babin, 2001; Menon \& Kahn, 2002; Hu \& Jasper, 2006; Ha \& Lennon, 2010). Shopping convenience, site design, customer communication, deal safety, reward, distribution, produce value and distinct fulfilled data are constituents of website personality which acts as a stimulus for the users resulting in a reaction of perception security, perception information worth, perception usability, trust satisfaction leading to consumer purchase intentions.

Theory of reasoned action (TRA) is based on the Performance is determined by an separate actions intention to adopt. Behavior intention is the function of two factors such as attitude towards behavior and subjective norms (Fishbein and Ajzen, 1980). Subjective norm is a general perception of an individual to perform/not perform a certain behavior. Attitude towards behavior is the function of individuals' belief that shows of behavior would attractiveness and normative belief and motivation to comply with the individual behaviors.

Technology Adoption Model (TAM) was changed by eliminating attitude variable established in TRA and showed that the connection among perceived ease of use, perceived usefulness, user behavior affected by intention acting as a mediator (Venkatesh \& Davis., 2000).

According to Davis (1989), the Technology Acceptance Model (TAM) is a common theory that is examined for technology acceptance. Also, perception usefulness intermediates the consequence of perception ease of use on behavioral intentions or it may not have any impact on it (Venkatesh Morris, 2000). As users become familiar with technology use, the effect of perceived ease of use gradually starts declining (Gefen, 2003). In the present context, the users are acquainted with the technology so it is likely that the impact of perception ease of use will be minimal. Thus, the present study does not include the influence of perception ease of use on the attitude of customers towards e-shopping stores. The study (Flavian, Guinaliu, and Gurrea, 2006) confirms this view. Perceived usefulness may be expressed as the extent of belief a person has about using technology that it would augment her/his performance (Davis, 1989). Unlike the perception ease of use and perception usefulness having substantial influence on behavioral purposes.

Roman proposed the concept of CPEOR and may be defined as the consumer's perceptions about the integrity and responsibility that protects customer interests by the company behind a shopping website when it attempted to covenant with customers in a protected, confidential, fair, and honest way. The Security, the privacy, the non-deception, and fulfilment/reliability are the four dimensions of the CPEOR scale. The uncertainty of incurring monetary losses occurs when dealing with a web site can be defined as the security concern. (Biswas Roman, 2007). Most of the online shoppers are fretful about the loss of their personal and financial information by potentially malicious people on breaching the technological data protection agreements (Marmorstein and Sarel 2006).

The transmission and storage of all personal information during the payment process creates the perception of security on e-commerce activity. That can be referred to the security perception (Chang and Chen (2009). As a different definition (Wolfinbarger and Gilly (2003) who clubbed the security and the privacy as a single factor, that the former includes the security in a payment made through cards and the privacy of data sharing through purchase platforms.

Long-Chuan Lu (2013) Adopted CPEOR scale (Roman (2007) is comprised of four magnitudes: Security, Privacy, nondeception, and fulfilment/reliability. Roman (2007) noted that for increasing the validity and clarity, the privacy and security need to be differentiated into two separate independent constructs. CPEOR had a great impact on consumer's expertise on the internet in general. That in turn considered as a strong forecaster of word of mouth (Roman and Cuestas (2008).

Sajeev Varki (2001) examined Lemon and Bolton (1999), the impact of the price perception and found an influence of value observations on behavioral intention. An empirical test reveals that proportional value perceptions have a commanding effect on purchaser value insights, complete purchaser satisfaction and behavioral purpose.

\section{Proposed model}




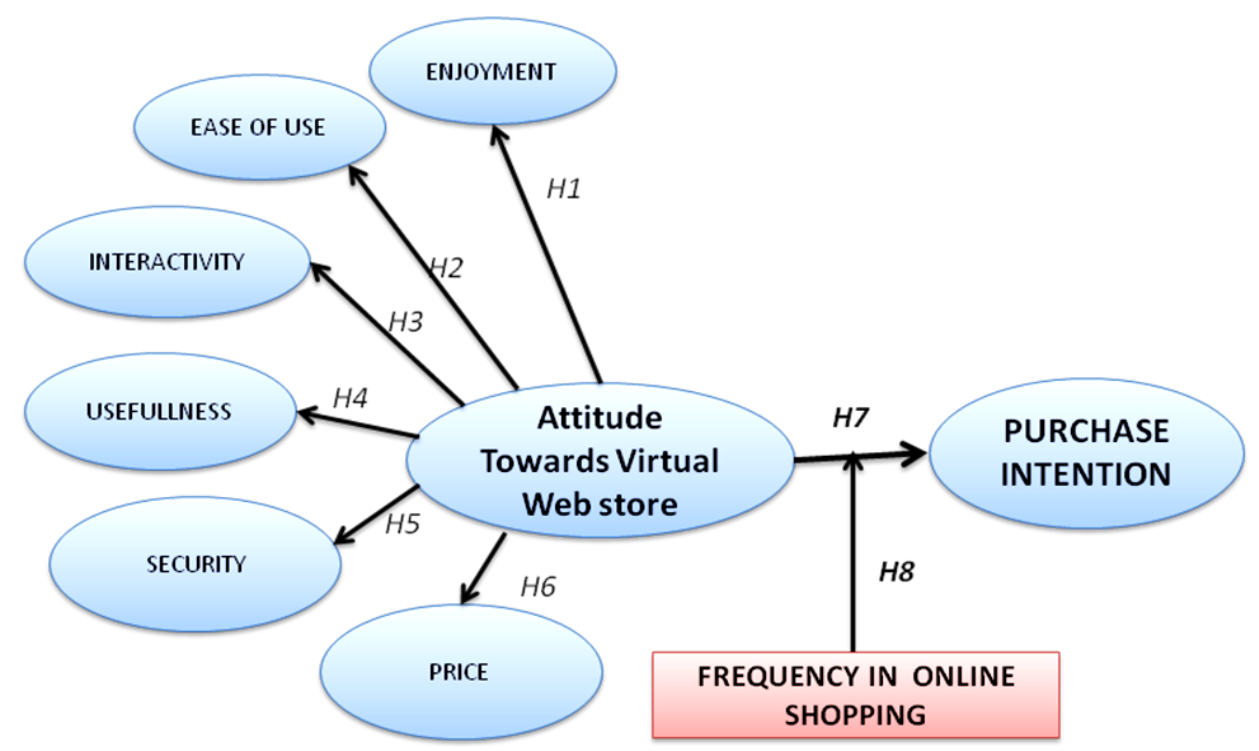

Fig -1: proposed model

Conceptual development and Hypotheses Development:

Online shopping has received much impetus from the last few decades both in terms of research and new opportunities for business developments by identifying the various motivating factors for it (Alijani et al., 2014). Technology Acceptance Model has emerged as the most popular model for investigating determinants of online shopping (Celik (2011); Kim (2013)

TAM model such as its lack of ability to identify various factors that influences the perception of consumers regarding perception usefulness, perception ease of use, perceived risk and satisfaction as well as e-shopping outcomes like trust, satisfaction and repurchase intention. Websites are the type of information systems which allow consumers to choose products and services according to their needs and requirements. It is a primary interface between retailer and consumer, yet very little is known about the impact of the web interface on consumer's intention to purchase online (Richard, 2005). The reason may be that earlier web design has been assumed as mere information technology paradigm (Yang et al. 2003).

\section{Methodology:}

An online survey questionnaire was developed to examine the attitude towards innovative shopping in virtual 3D online websites environment. The questionnaire made by the help of online survey tool-type form which enabled to add video demonstration for giving awareness of 3D virtual store environment. This helped the respondents to get an idea about the concept of the 3D virtual store. The constructs were restrained using a five-point scale ranging from 1 to 5 (strongly agree to strongly disagree), twenty items used calculate four latent construct, Enjoyment (EN), Interactivity (IR), Usefulness (US), Ease of Use (EU),. The online survey administered to online shoppers who are selected randomly from a pool of online purchasers of sample based on the criteria that respondents must know using web sites for their shopping and usage of such online shopping websites is frequent. The purposeful sampling methodology adopted as the respondent had enough experience with the online shopping websites. A mail containing the online survey link mailed to more than 1000 respondents through their emails ids and was requested to take part in the survey. On clicking the link provided in the mail, survey questionnaire will open up and the respondent can participate to survey. First, the respondent was asked to watch the video demonstration of the $3 \mathrm{D}$ virtual web environment. The respondent was also asked to give names of some shopping sites and products that they used to shop. In a total of 375 completed questionnaires 320 has taken for analysis to validate the measurement and structured model.

\section{Enjoyment perception:}

Enjoyment has been defined as the perceived entertaining and fun that felt by the shoppers to the extent to which online shopping they do. Researchers have pleasure of significant impact on consumer's attitude and behaviours, which encourage the consumer intention to revisit (Koufaris et al (2001), Koufaris (2002); Hampton- Sosa and Koufaris (2005), Chiu et al (2009), Gehrt et al (2012). Some of the researchers have identified that the hedonic aspect on the e-shopping such as pleasure, pleasure-seeking and the community experience as the significant factors of the e-shopping (Childers et al. (2001), Parsons (2002) Joines et al. (2003), Ha and Stoel (2009) have found the enjoyment impact on perception usefulness. some of the researchers supported this also Lee et al. (2005) that pleasure is a drives user to use new know-how. Based on the above discussion hypotheses is postulated:

H1: perceived Enjoyment has a positive effect on Attitude towards virtual Shopping 


\section{Interactivity perception}

The online shopping environment is supportive in providing much more information than offline environments. Better informational base helps the consumers to make more informed decisions that make them increase their satisfaction in the online shopping process (Glazer, 1991) in an online shopping context refers to the degrees of communication between the consumer and the e-retailer, anywhere at any time The interactivity of the e-retailer websites offers the utilitarian benefit ie; the saving time/effort, reducing risks and increasing searches usefulness and hedonic benefit of enjoyment Klein (1998), Srinivasan et al. (2002).

$\mathrm{H} 2$ : Interactivity perception has positive effects on Attitude towards the virtual shopping

\section{Perceived ease of use}

In this study, the construct ease of use measuring the customers' belief in the ease of learning and using the proposed 3D virtual web environment. According to Bisdee (2007) perceived ease of use could implicit as the degree to which the online shopping customer have faith in that shopping will be free. Research studies have found that PEOU is a significant predictor of attitude towards technology-based services (Dabholkar, 1994; Heijden, 2000). Van der Heijden (2004) perceived ease of use is a hedonic-oriented factor which increases with the convenience of shopping website and interaction of the consumer with the web will increase (Barkhi and Wallance, 2007) have found there is a positive relationship between PEOU and the perceived usefulness (Cyr et al., 2007). Kaplan et al. (2007) have observed that the effect of PEOU on behavioral intention is mediated through perceived usefulness. Besides, PEOU has a significantly positive effect in an internet shopping environment (Kamarulzaman, 2007). Thus, the following hypotheses have been formulated

H3: Perceived Ease of use has a positive effect on Attitude towards the virtual shopping

\section{Perceived usefulness}

The significant effect of perceived usefulness to online shopping behavior can be seen in Spain but few researchers such as (Aghdaie et al. (2011) recommended that It has an insignificant effect on internet purchasing behavior in Iran. This may be caused due to diverse viewpoints of respondents in developing and developed countries on the aspects of the price of the product, its quality, and durability as well as characteristics of the related products that act as main drivers for purchase decisions and vary in both types of countries (Ahmed, 2012). A study in Malaysia by Ndubisi \& Jantan (2003) revealed that the use of an information system is impacted directly and imperatively by perceived usefulness of a specific system. Few studies demonstrate the significant impact of perceived usefulness on the purchase intention of customers when using the internet (Enrique et al, 2008; Kim \&
Song, 2010; Xie et al, 2011). Kim \& Song (2010) supported the view that valuable information is needed by observed that perceived usefulness has a positive relationship with the esatisfaction in banking services adoption. Based on the above discussions following hypothesis has been formulated

H4: Perceived Usefulness has a positive effect on Attitude toward the virtual shopping

\section{Price perception of security perception}

Bolton and Lemon (1999), says the effect of the price perception and found impact of price perceptions on behavioral-intention. Sajeev Varki, Mark Colgate (2001) reveals that proportional price perceptions having an influential effect on customer value perception, customer satisfaction, and behavioral intentions. Customers are more optimistic in price perception about the e-retailers that shows further reliability in fulfilment. Between shopping, convenience and price perception have significant and strong correlations. Pingjun Jiang Bert Rosenbloom (2005) pointed out that the consumers may be ready to pay for their expediency for purchasing from these e-retail stores. Further research approaches on this issue are needed to be carried out by e-retailers point of view with greater reliability of services that may charge a higher or low price.

The consequence of price perception of customer satisfaction is studied and tested by using relative measures of price perception on the competition.

H5: Price perception positively influence on Attitude towards virtual shopping

\section{Security perception:}

The present study has expressed perceived safety in three components such as privacy, security and reliability, Parasuraman (2000) has argued insecurity and negatively affect the technology adoption.

Security and privacy are closely related, this study has taken them as distinct constructs. privacy is a conscious effort of eretailor in dealing with customer data and information while security deals with the inadvertent compromise of the customer data of the third party

H6: Perception of website security has a positive influence on Attitude towards virtual shopping

\section{Results:}

The data is collected by administering the online question through email. the total collected sample are 320 out of which 183 are males and 137 females are in the age group of 26- 34 years. SEM was done to conform to the casual relations between the latent constructs and testing the hypothesis of this study. First, conducted an EFA with principal axis factoring for all constructs 
that helped to delete items that poorly performed (Table-1 summaries the items taken after deleting items that are poor performed due to weak or cross-loading). subsequently,

\section{Table - 1: Descriptive Statistics of Construct Variables}

$\begin{array}{lllr}\text { Construct } & \mathbf{N} & \text { Mean } & \text { Standar } \\ \text { EU } & 320 & 2.67 & 0.802 \\ \text { US } & 320 & 2.77 & 0.919 \\ \text { IR } & 320 & 2.78 & 0.857 \\ \text { EN } & 320 & 2.65 & 0.864 \\ \text { SC } & 320 & 2.75 & 0.893 \\ \text { PC } & 320 & 2.61 & 0.833 \\ \text { PI } & 320 & 2.69 & 0.800\end{array}$

Source: Analysis of the primary data collected through questionnaire

Table-1: Illustrates the mean and standard deviation of various variables considered in the present study. It is observed from the table that perceived Interactivity has the highest mean score (2.78) and perceived pricing has the lowest mean score (2.61) among the latent variables.

Consumers are not ready to compromise with the shopping atmosphere as it is the first visual appearance between e-store and consumers. The credibility and quality of the web store are influenced by visual and graphic appearance. These findings are in context to the findings of Rosen and Purinton (2004) who have demonstrated that sensory stimuli play a significant role in promoting online sales and e-store visits. Table 4.8 reveals that interactivity has the highest mean (2.78) and the standard deviation is below 1 .

Respondents have agreed that privacy is one of the key dimensions. Respondents are more concerned about the privacy of their personal information and security. The consumer will never compromise on the privacy component of online shopping. These findings are following the results of Pavlou (2011) who has emphasized the privacy of the information as the determinants of online- related Behaviour reactions or intentions.

The perceived enjoyment has a mean of 2.65 and standard deviation below 1 that shows this kind of virtual reality web store make the users feel that this kind of platform would be comfortable and enjoyable.

The TAM determinants, Perceived ease of use has a mean (2.67) and perceived usefulness has a mean (2.77). The standard deviation of both the variable is below 1 . This shows that respondents perceive that virtual reality web store is easier to use and is useful. Respondents agree that the ease of use is a very important component of the attitude toward virtual reality web store and should be catchy, navigable and friendly and easy to use

The mean score of perceived pricing is 2.61 and standard deviation below 1 , which has the lowest value that shows respondents in more agreement area that the pricing factor having a key role in any kind of technology-assisted shopping platform.

Table-1: illustrates that the mean score of outcome behavioral intention to purchase is (2.69). The standard deviation is below 1. Respondents agree that they have a high preference for behavioral intention to purchase. It is understood that respondents are willing to remain with this kind of technologyassisted web store and are ready to visit for purchase.

\section{Reliability and Validity}

Reliability denotes the degree to which an item or a group of items give consistent results to what is it proposed to determine repeatedly (Hair et al., 2009). Internal consistency and reliability of the attributes have been assessed through reliability coefficient (Cronbach's Alpha) and Composite Reliability (CR). The estimate of Cronbach's Alpha ranges from $0-1$ and the acceptable threshold is .60 or greater. Cronbach's Alpha has been examined for each component/factor in SPSS. Table -2 shows the reliability coefficient of all the 6 variables which is above .60 thereby indicating internal consistency and reliability of the sample data. The CR of both the measurement models has been examined in CFA. CR is the evaluation of the average variance shared between the latent factor and its items. CR has been derived from the validity tests of the scale used in this study. The following conditions are necessary to ensure convergent as well as discriminant validity:

The results below show that the $\mathrm{CR}$ of the extracted constructs considered in the measurement model is found to be greater than 0.7 and AVE of each construct is greater than 0.5. Hence, 
the convergent validity of the constructs in the measurement model is ensured. In addition to this AVE of each construct extracted is found to be greater than MSV which shows the presence of discriminant validity among the constructs

Table-2: Reliability and validity

$\begin{array}{lllllllll}\text { CR } & \text { AV } & \text { MS } & \text { SECURI } & \text { ENJOYM } & \text { EAS } & \text { INTERACTI } & \text { USEFULN } & \text { PRICI } \\ & \text { E } & \text { V } & \text { TY } & \text { ENT } & \text { E } & \text { VITY } & \text { ESS } & \text { NG } \\ & & & & & \text { OF } & & \\ & & & & & \text { USE } & & \end{array}$

$\begin{array}{lllll}\text { SECURITY } & 0.88 & 0.66 & 0.21 & \mathbf{0 . 8 1 3} \\ 6 & 2 & 1 & \end{array}$

$\begin{array}{llllll}\text { ENJOYMENT } & 0.90 & 0.69 & 0.03 & 0.190 & \mathbf{0 . 8 3 5}\end{array}$

$\begin{array}{lllllll}\text { EASE OF USE } & 0.87 & 0.62 & 0.06 & 0.256 & 0.092 & \mathbf{0 . 7 9}\end{array}$

$\begin{array}{llll}0 & 6 & 6 & 1\end{array}$

$\begin{array}{llllllll}\text { INTERACTIV } & 0.82 & 0.54 & 0.07 & 0.200 & 0.149 & 0.21 & \mathbf{0 . 7 3 7} \\ \text { ITY } & 5 & 4 & 9 & & & 0 & \end{array}$

$\begin{array}{lllllllll}\text { USEFULNESS } & 0.90 & 0.69 & 0.10 & 0.150 & 0.000 & 0.21 & 0.092 & \mathbf{0 . 8 3 2} \\ & 0 & 3 & 4 & & & 2 & \end{array}$

$\begin{array}{lllll}0 & 3 & 4 & 2\end{array}$

$\begin{array}{llllllllll}\text { PRICING } & 0.90 & 0.70 & 0.21 & 0.459 & 0.157 & 0.18 & 0.281 & 0.323 & \mathbf{0 . 8 4 0}\end{array}$

$\begin{array}{llll}5 & 6 & 1 & 2\end{array}$

Source: Analysis of the primary data collected through questionnaire

Table-3: Reliability and validity Analysis results

$\begin{array}{llllll}\text { Constructs } & \text { Items } & \begin{array}{l}\text { Standard } \\ \text { Factor }\end{array} & \begin{array}{l}\text { Average } \\ \text { Variance }\end{array} & \begin{array}{l}\text { Composite } \\ \text { Reliability }\end{array} & \begin{array}{l}\text { Cronbach's } \\ \text { Alpha }\end{array} \\ & \text { Loading } & \text { Extracted } & & \\ \text { ENJOYMENT } & \text { EN2 } & 0.897 & 0.697 & 0.901 & \\ & \text { EN3 } & 0.889 & & \end{array}$


EN4 $\quad 0.753$

\begin{tabular}{|c|c|c|c|c|c|}
\hline \multirow[t]{4}{*}{ EASE OF USE } & EU1 & 0.731 & 0.626 & 0.870 & 0.899 \\
\hline & EU2 & 0.871 & & & \\
\hline & EU3 & 0.798 & & & \\
\hline & EU4 & 0.758 & & & \\
\hline \multirow[t]{4}{*}{ INTERACTIVITY } & IR1 & 0.681 & 0.544 & 0.825 & 0.824 \\
\hline & IR2 & 0.660 & & & \\
\hline & IR3 & 0.802 & & & \\
\hline & IR4 & 0.795 & & & \\
\hline \multirow[t]{4}{*}{ USEFULNESS } & US1 & 0.768 & 0.693 & 0.900 & 0.899 \\
\hline & US2 & 0.865 & & & \\
\hline & US3 & 0.890 & & & \\
\hline & US4 & 0.801 & & & \\
\hline \multirow[t]{4}{*}{ SECURITY } & $\mathrm{SC} 1$ & 0.881 & 0.662 & 0.886 & 0.880 \\
\hline & $\mathrm{SC} 2$ & 0.857 & & & \\
\hline & $\mathrm{SC} 3$ & 0.804 & & & \\
\hline & $\mathrm{SC} 4$ & 0.700 & & & \\
\hline \multirow[t]{4}{*}{ PRICING } & PC1 & 0.807 & 0.706 & 0.905 & 0.903 \\
\hline & $\mathrm{PC} 2$ & 0.881 & & & \\
\hline & PC3 & 0.852 & & & \\
\hline & PC4 & 0.818 & & & \\
\hline
\end{tabular}

Source: Analysis of the primary data collected through questionnaire 


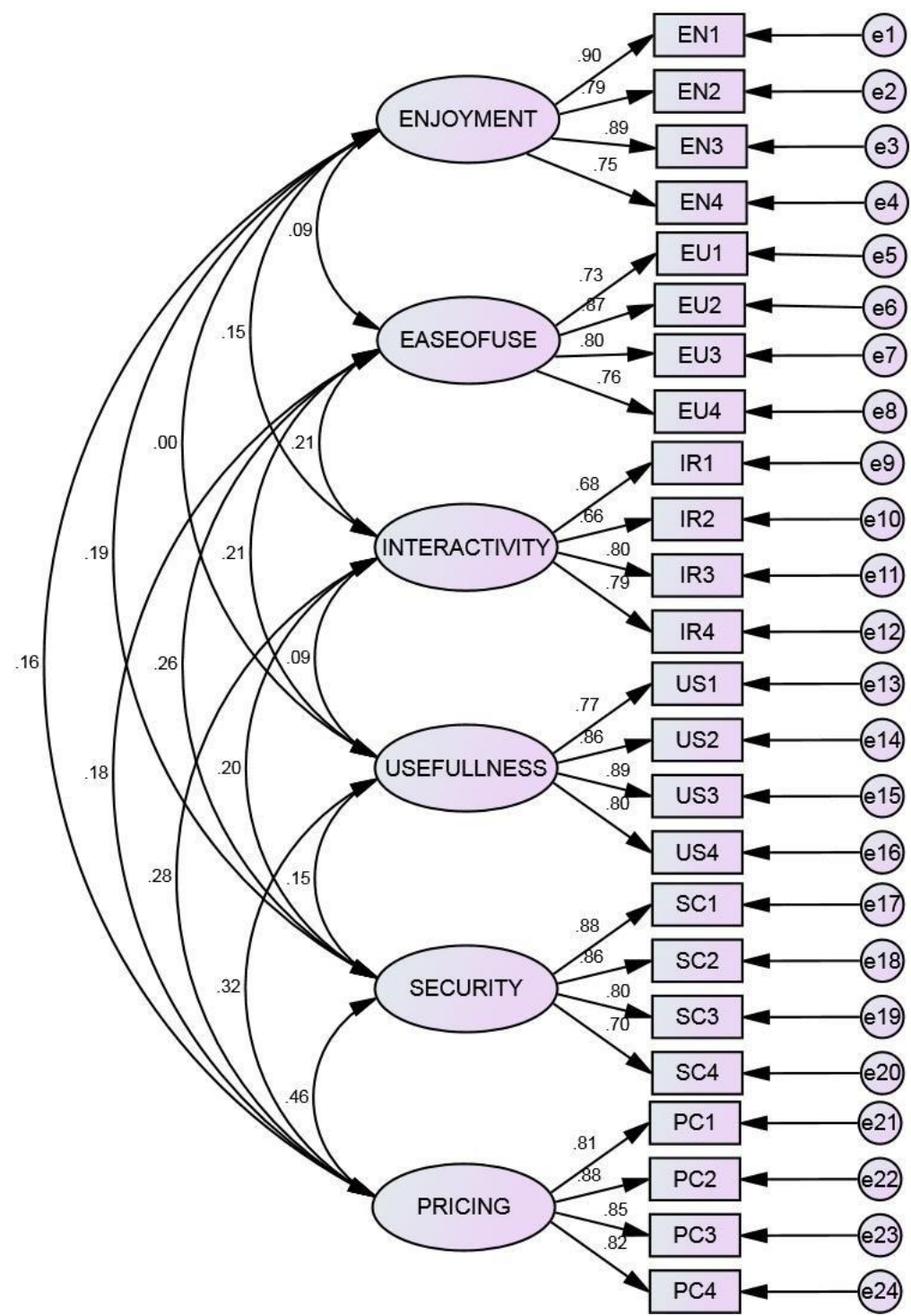

Fig -2: Measurement Model

The CFA diagram of measurement model represents that there are six constructs considered for CFA analysis. All the six constructs are used to measure the attitude towards virtual reality web store. As shown in the figure these constructs are represented by large ellipses. The items used to measure the constructs are shown with the help of rectangles attached by the constructs. The arrows are started from the constructs and headed the arrows are started from the constructs and headed towards the measured variables which represent that all the constructs considered in the study are reflective. The error terms connected with the rectangle measured items represented the unexplained variance if any left in explaining the variables by the constructs. The constructs considered for CFA analysis are joined by two-sided arrows representing the covariance between the constructs.

Table:4 Regression Analysis in the table model

$\begin{array}{lllllll}\text { Items } & & \text { Constructs } & \text { Estimate } & \text { S.E. } & \text { C.R. } & \text { P } \\ \text { EN1 } & <--- & \text { ENJOYMENT } & 0.897 & 0.091 & 16.503 & * * * \\ \text { EN2 } & <-- & & 0.791 & 0.072 & 14.429 & * * * \\ \text { EN3 } & <--- & & 0.889 & 0.082 & 16.378 & * * * \\ \text { EN4 } & <--- & & 0.753 & & & \\ \text { EU1 } & <--- & \text { EASEOFUSE } & 0.731 & 0.077 & 12.852 & * * *\end{array}$




\begin{tabular}{|c|c|c|c|c|c|}
\hline EU2 & $<---$ & & 0.871 & 0.084 & 15.141 \\
\hline EU3 & $<---$ & & 0.798 & 0.077 & 14.085 \\
\hline EU4 & $<---$ & & 0.758 & & \\
\hline IR1 & $<---$ & INTERACTIVITY & 0.681 & 0.071 & 11.623 \\
\hline IR3 & $<--$ & & 0.802 & 0.076 & 13.359 \\
\hline IR4 & $<---$ & & 0.795 & & \\
\hline US1 & $<---$ & & 0.768 & 0.068 & 14.905 \\
\hline US2 & $<---$ & USEFULLNESS & 0.865 & 0.064 & 17.343 \\
\hline US3 & $<---$ & & 0.89 & 0.062 & 17.903 \\
\hline US4 & $<---$ & & 0.801 & & \\
\hline $\mathrm{SC} 1$ & $<---$ & & 0.881 & 0.086 & 14.267 \\
\hline $\mathrm{SC} 2$ & $<---$ & SECURITY & 0.857 & 0.071 & 13.981 \\
\hline SC3 & $<---$ & & 0.804 & 0.08 & 13.238 \\
\hline $\mathrm{SC} 4$ & $<--$ & & 0.7 & & \\
\hline PC1 & $<---$ & & 0.807 & 0.07 & 16.389 \\
\hline $\mathrm{PC} 2$ & $<---$ & PRICING & 0.881 & 0.067 & 18.428 \\
\hline PC3 & $<---$ & & 0.852 & 0.057 & 17.655 \\
\hline PC4 & $<--$ & & 0.818 & & \\
\hline
\end{tabular}

Source: Analysis of the primary data collected through questionnaire

\section{Structural equation modelling}

The different causal hypotheses that have been formulated in the proposed model and were empirically tested on sample data set by constructing a Structural Model (Fig:2), which incorporates all the six latent constructs undertaken in the proposed model. Therefore, predictive power and deterministic power of different variables were estimated through Standardized Regression Weight (SRW) and the coefficient of determination in Structural Modeling

Attitude towards virtual reality web store s measured with the help of six latent constructs that mentioned below

$>$ Perception Enjoyment

$>$ Perception Interactivity

$>$ Perception Ease of Use

$>$ Perception Usefulness

$>$ Perception Privacy/Security

$>$ Perception Price
The primary data the responses are collected on a five-point interval scale where 1 indicates strongly agree and 5 means strongly disagree. The following hypothesizes are framed to test the relationship path in the Structural Equation Modelling approach.

H1: perception Enjoyment has a positive effect on Attitude towards virtual reality shopping

H2: perception Ease of use has a positive effect on Attitude toward the virtual reality shopping

H3: perception Interactivity has a positive effect on Attitude toward the virtual reality shopping

H4: perception Usefulness has a positive effect on Attitude toward the virtual reality shopping

H5: perception security has a positive influence on Attitude towards virtual reality shopping

H6: perception pricing positively influences on Attitude towards virtual reality shopping 
Table-5: Results of the structural model

PATHS

$\begin{array}{lll}\text { Std. } & \text { Std.Error } & \text { Critical } \\ \text { Estimates } & & \text { Ratio }\end{array}$

P- Decision R2

$<--$

0.058

4.54

H1

ENJOYMENT

ATTITUD 0.262
E

value

$\mathrm{H} 2$

EASE OF USE

$<---\quad$ ATTITUD $\quad 0.253$

0.041

6.18

$* * *$

Supported

0.42

H3

INTERACTIVITY

$<--$

ATTITUD $\quad 0.323$

0.048

6.681

$* * *$

Supported

0.46

E

H4

USEFULNESS

$\begin{array}{ll}<-- & \text { ATTITUD } \\ \text { E } & 0.269\end{array}$

0.049

5.494

***

Supported

0.37

H5

SECURITY

$\begin{array}{ll}<--- & \text { ATTITUD } \\ \text { E } & 0.495\end{array}$

0.051

9.623

$* * *$

Supported

0.67

H6

PRICING

$\begin{array}{ll}<--- & \text { ATTITUD } \\ \text { E } & 0.487\end{array}$

0.045

10.841

Supported

0.70

\section{Source: Analysis of the primary data collected through questionnaire}

These findings provide a fruitful prospect to the e-retailers to capitalize on the increased site traffic and enhanced successful shopping transaction by reflecting both intrinsic and extrinsic motivation elements in their shopping interface. The results shown in Table-5 reveal that perceived enjoyment has a significantly positive impact on the attitude towards virtual reality web store. Standard Regression Weight is .262 and a critical ratio of 4.54 significant at .05 . It is also observed from the structural model that Enjoyment construct is one of the significant dimensions to create an attitude towards virtual reality web store and gives the highest contribution. Based on these results (P-value <0.005), hypothesis, H1 the Perceived Enjoyment has positive effects on Attitude towards virtual store environment, is supported. It is understood from the results that consumers having a perception that virtual reality web store shopping is enjoyable.

Results have further revealed that Perceived ease of use has a significantly positive impact on the attitude towards virtual reality web store with Standard Regression Weight 0.253 and critical ratio 6.18 significant at .05 . Hence, supports hypothesis $\mathrm{H} 2$ that Perceived Ease of use has a positive effect on Attitude towards the virtual reality web-store platform. These findings got support from the previous studies carried out in online shopping platforms by Devaraj et al. (2002). These researchers have argued that improvement in perceived ease of use with another interactive shopping platform will be influential in contributing to increased performance and easiness in using such platforms so that the findings of this study in correspondence with them

The result in Table 5 shows the Perceived Interactivity has a significantly positive impact on the attitude towards virtual reality web store with Standard Regression Weight 0.323 and critical ratio 6.681 significant at .05 . Hence, supports hypothesis $\mathrm{H} 3$ that Perceived Interactivity has a positive effect on Attitude towards the virtual reality web-store platform. It is observed that interface communication and information in terms of interactivity is considered as a significant dimension. This finding shows 
that interactive shopping platform design is crucial for developing consumer relationships, facilitating consumer support and enhancing usability to a customer. A poorly developed and designed platform can be irritated or frustrate the online customer and deprive him of undertaking shopping tasks. Creating a positive and successful platform design is decisive in catching the online customer's minds and hearts

The results shown in Table 5 revealed that perceived usefulness has a significantly positive impact on the attitude towards virtual reality web store with Standard Regression Weight 0.269 and critical ratio 5.494 significant at .05. Hence, supports hypothesis H4 that Perceived Usefulness has a positive effect on Attitude towards the virtual reality web-store platform. The level of attachment among customers will increase when they perceive online shopping useful and beneficial than offline shopping resulting in reduced operational costs, convenience gains, service access anytime and anywhere. Further, the enhanced trust level will result in a higher level of satisfaction among customers.

From the results presented in the Table 5 reveal that perceived privacy/safety has a significantly positive impact on the attitude towards virtual reality web store with Standard Regression Weight 0.495 and critical ratio 9.623 significant at .05. Hence, supports hypothesis H5 that the Perceived Security dimension has a positive effect on Attitude towards the virtual reality web-store platform. It is understood from the results that customers will more likely to purchase from online retailers that require a minimum amount of personal information and giving security in transactions and does not share customer information with third parties.

Table 5 depicts that the perceived price significantly positive impact on the attitude towards virtual reality web store with Standard Regression Weight 0.487 and critical ratio 10.841 significant at .05. Hence, supports hypothesis H6 that Perceived price has a positive effect on Attitude towards the virtual reality web-store platform. It has been found that customers likely to buy through online platforms when they perceive many benefits as compared to the traditional mode of shopping. Due to these benefits associated with online shopping, that enhances online shopping activity, Hence the price of products is an important aspect. This statistical result provides support to the hypothesis postulated. Therefore, online retailers need to focus on these factors to understand the actual behavior of the customer's rather than acquiring new customers by offering huge discounts. These sustainable developments in consumer behavior will help in enhancing the trust level among the consumers and e-retailers will hit profits Discriminant validity is opposite to convergent validity and denotes the degree of distinctiveness from other constructs. Construct validity has been examined by calculating the Average Variance Extracted (AVE) using CFA. Discriminant validity is established by comparing AVE with the square of the correlation coefficient between the constructs (Byrne, 2001). When AVE observed for a construct is higher than the square of correlation coefficient (Fornell and Larcker, 1981) if the correlation between constructs is less than 0.85 (Kline, 2005 ) it is said to possess discriminant validity (Malhotra and Dash, 2010).

\section{Analysis:}

The results from the calculation in this study verified the test criterion of discriminant validity. For the convergent validity test, the estimates of variance extracted are tested. All of the average variance extracted for the six constructs examined were above the standard value and the level of signifying that indicators successfully represent the latent variables and showing convergent validity. Afterwards tested the chi-square values and the overall goodness of fit. The adjusted GFI 0.847 and goodness of fit index GFI 0.826 of this result shows values greater than 0.8. According to Hair et al. (2006), GFI (Goodness of Fit Index) is one of the important fit indices for measuring SEM model fitness as it measures the covariance matrix among indicator variables. The present study has used absolute, incremental and parsimonious fit indices to examine model goodness-of-fit (Ferdinand, 2006; Hair et al., 2006). Hence, acceptable. Amongst Absolute Fit Index the study has used GFI and RMSEA to measure absolute fit as these are most often used in marketing research. It compares the discrepancy value of the saturated model and the discrepancy value of the tested model. GFI value above 0.80 indicates that the model is fit (Santoso, 2007). The residual estimates RMSEA found to be 0.073 RMSEA indicates the extent to which a model fits a population. It compares the lack of fit of a model assessing its misspecifications to that of a corresponding saturated model relative to the model degrees of freedom. It is sensitive to model misspecified factor some studies have recommended that value below 0.08 is reasonably acceptable. However, if possible, values below 0.07 (Miller, 2009); preferably below 0.06 (Tabachnick and Fidell, 2007) are good Incremental Fit Index examines the relative fitness of the proposed model in comparison to the baseline model or null model. The CFI value 0.91 and the and the IFI value of 0.92 are in consideration level to meet the determination criterion of value greater than 0.9. After the analysis, the results obtained indicate that the proposed model was significantly within the acceptable value range and it is consistent for structural relations model analysis. In this study, we independently explained the causal relation between every construct given that entertainment interactivity, ease of use and usefulness having direct influence to attitude towards virtual web store. For $\mathrm{H}_{1}$ standardized coefficient shows the estimates of 0.262 and p-value less than $0.001, \mathrm{H}_{2}$ standardized coefficient of 0.253 and p-value less than 0.001 and then for $\mathrm{H}_{3}$ standardized coefficient is 0.323 and p-value is less than 0.001 and for the hypotheses $\mathrm{H}_{4}$ standardized coefficient is 0.269 and p-value is 0.001 for the $\mathrm{H}_{5}$ the standardized coefficient 0.495 and p-value is less than 0.001 for the $\mathrm{H}_{6}$ the 
standardized coefficient is 0487 and the p-value is less than 0.001. All the path coefficients of perceptional attitude towards 3D virtual web store are significant and supported respectively hypothesis. So, the findings support the proposed model.

\section{Conclusion and managerial implications:}

This study, proposing a model with constructs combined from Uses and Gratifications theory (McGuire1974; Herzog 1944; Eighmey 1997) and TAM, attempted to investigate the empirical shreds of evidence of perceived attitude towards innovative virtual shopping environment. Based on the study the enjoyment and interactivity in the innovative virtual online shopping web store, consumer shows influencing shopping experience. Ease of use and usefulness of innovative threedimensional web store platform, consumers feel exceptional shopping experience. Same as in offline stores there is touch and feel effects creates more satisfaction to purchase from such virtual stores than normal shopping websites. Particularly, satisfaction and unique shopping experience lead as the consequences of repurchase intention. As enjoyment, interactivity, usefulness and ease of use are the antecedents of attitude towards the 3D online virtual store the consequences can be satisfaction and repurchase intention. The results indicated Internet users who recognize the unique idea of visualization and interactivity in $3 \mathrm{D}$ virtual store websites as entertaining and enlightening. In general customers like such kind of innovations for their online shopping environment. This shows a positive attitude towards the $3 \mathrm{D}$ virtual store. This finding of the study offers an innovative digital business model of creating three-dimensional virtual store environments. The electronic marketers should go beyond from normal business models with two-dimensional store platforms to creating a potential satisfied user and repeated purchasers. Ultimately, repurchase intention shows loyalty and consumer satisfaction to such virtual web stores are the major factors to the success of e-business. The present study contributed to the literature by combining interrelated established model variables as antecedents by using the SEM method. This study can be extending the scope of investigating the consequences of empirically. Future research works are inviting to authenticate the finding of the study in different sample settings.

\section{Acknowledgement:}

I thank my Scholar Mr. Ratheesh.S for his valuable help in writing the paper

\section{References:}

[1]. Agarwal, R., \& Karahanna, E. (2000). Time flies when you're having fun: cognitive absorption and beliefs about information technology usage. MIS Quarterly, 24(4), 665-694.
[2]. Accard, J.,\& Davidson, A. R. (1975).A comparison of two models of social behavior: Results of a survey sample. Sociometry, 38, 497-517.

[3]. Angela V. Hausman, Jeffrey Sam Siekpe The effect of web interface features on consumer online purchase intention, Journal of Business Research 62 (2009) 5-13

[4]. Ariely, D. (2000). Controlling the information flow: effects on consumers' decision making and preferences. Journal of Consumer Research, 27(2), 233-249

[5]. Blanca Hernandez Julio JimenezM.José Martín, (2009),"Adoption vs acceptance of e-commerce: two different decisions", European Journal of Marketing, Vol. 43 Iss 9/10 pp.1232 - 1245

[6]. Charles Dennis Bill Merrilees Chanaka Jayawardhena Len Tiu Wright, (2009),"E-consumer behaviour", European Journal of Marketing, Vol. 43 Iss 9/10 pp. $1121-1139$

[7]. Chanaka Jayawardhena Len Tiu Wright, (2009),"An empirical investigation into e-shopping excitement: antecedents and effects", European Journal of Marketing, Vol. 43 pp. 1171 - 1187

[8]. Chen, P.-Y. and Hitt, L.M. (2002), "Measuring switching costs and the determinants of customers retention in internet-enabled businesses: a study of the online brokerage industry", Information Systems Research, Vol. 13 No. 3, pp. 255-76

[9]. Chen, S.Y., Magoulas, G.D., Dimakopoulos, D., 2005. A flexible interface design for web directories to accommodate different cognitive styles. J.Am. Soc. Inf. Sci. Technol.56 (1), 70-83

[10]. Davis FD. Perceived usefulness, perceived-ease-ofuse and user acceptance of information technology. MIS Quart 1989; 13:319-40

[11]. Eroglu, S.A., Machleit, K.A. and Davis, L.M. (2001), "Atmospheric qualities of online retailing: a conceptual model and implications", Journal of Business Research, Vol. 54, pp. 177-84.

[12]. Field, J.M., Heim, G.R. and Sinha, K.K. (2004), "Managing quality in the e-service system: development and application of a process model", Production and Operations Management, Vol. 13 No. 4, pp. 291-306

[13]. Fornell, C., Larcker, D.F., 1981. Evaluating structural equation models with unob- servable variables and measurement error. J. Market. Res. 18 (1), 39-50.

[14]. Hui-Fei Lin and Chi-Hua Chen 2017 Combining the Technology Acceptance Model and Uses and Gratifications Theory to examine the usage behavior of an Augmented Reality Tour- sharing Application, Symmetry 2017, 9, 113; doi: 10.3

ISSN (Print): 2204-0595 ISSN (Online): 2203-1731 
390/sym9070113

[15]. Jacoby, J., Szybillo,G.J. and Berning, C.K. (1976), "Time and consumer behavior: an interdisciplinary overview", Journal of Consumer Research, Vol. 2, pp. 320-39

[16]. Koenig-Lewis, N. and Palmer, "Experiential values over time - a comparison of measures of satisfaction and emotion," Journal of Marketing Management (24:1-2), 2008, pp. 69-

[17]. Long-Chuan Lu Hsiu-Hua Chang Shih-Ting Yu, (2013),"Online shoppers' perceptions of e- retailers' ethics, cultural orientation, and loyalty", Internet Research, Vol. 23 pp. 47 -

[18]. Moon, J. Y., \& Kim, Y. K. (2001). Extending the TAM for a World-Wide-Web context.

[19]. Information \& Management, 38, 217-230

[20]. Mcguire, William J. (1974), Psychological Motives and Communication Gratification, in The Uses of Mass Communications, Jay G. Blumler and Elihu Katz, eds., Beverly Hills.

[21]. Oliveira, P., Roth, A.V. \& Gilland, W. (2002). Achieving competitive capabilities in e-service. Technological Forecasting and Social Change, 69, 721-39. Parasuraman, A., Rajat Gera, (2011),"Modelling e-service quality and its consequences in India: an SEM approach", Journal of Research in Interactive Marketing, Vol. 5 Iss 2/3 pp. 203

[22]. Pingjun Jiang Bert Rosenbloom , Customer intention to return online: price Perception, attribute- level performance and satisfaction unfolding over time, European Journal of Marketing Vol. 39 No. 1/2, (2005) pp. 150-174

[23]. Sajeev Varki, Mark Colgate, The Role of Price Perceptions in an Integrated Model of Behavioral Intentions-Journal of Service Research, Volume 3, No. 3, (2001)232-240

[24]. Sejin Ha Leslie Stoel, (2012),"Online apparel retailing: roles of e-shopping quality and experiential e- shopping motives", Journal of Service Management, Vol. 23 Issue 2 pp. 197-215

[25]. Sejin Ha , Leslie Stoel (2009) Consumer e-shopping acceptance: Antecedents in a technology acceptance model Journal of Business Research 565-571

[26]. Terry L. Childers, Christopher L. Carr, Joann Peck, Stephen Carson Hedonic and utilitarian motivations for online retail shopping behavior Journal of Retailing, (2001), 77(4),

[27]. Wakefield, K.L. and Baker, J. (1998), "Excitement at the mall: determinants and effects on shopping response", Journal of Retailing, Vol. 74 No. 4, pp. 515-31

[28]. Xueming Luo Uses And Gratifications Theory And E-Consumer Behaviors: A Structural Equation
Modeling Study, Journal of Interactive Advertising, Vol 2 No 2 (2002), pp. 34-41

[29]. Yael Benn , Thomas L. Webb , Betty P.I. Chang, John Reidy What information do consumers consider and how do they look for it, when shopping for groceries online ?-Appetite 89 (2015) 265-273

[30]. Ziqi Liao Xinping Shi, (2009),"Consumer perceptions of internet-based e-retailing: an empirical research in Hong Kong", Journal of Services Marketing, Vol. 23 Iss 1 pp. $24-30$

[31]. Ratheesh S and Dr. Byram Anand (2019) 'Customers' Attitude towards Shopping Environment: An Empirical Investigation to Antecedents of Technology adaptation with 3D Virtual Reality Shopping Web Store" International journal of Research and analytical review , special issue ,January 2019 ,page no 55-60

[32]. Ratheesh S and Dr. Byram Anand (2019) Unpublished thesis entitled "Antecedents of Attitude Towards Virtual Reality Web Store and Purchase Intention: An Empirical Investigation" submitted to Pondicherry University, Pondicherry, India

Online / Websites resources: accessed from $1^{\text {st }}$ December to $4^{\text {th }}$ December, 2020

[33]. https://www.realitytechnolgies.com/virtual-reality/

[34]. https://thinkmobiles.com/blog/virtual-reality-retail/

[35]. https://medium.com/frulix/virtual-reality-in-ecommerce-future-is-here-a16683a00a62

[36]. https://ecommercegermany.com/blog/ar-and-vr-ine-commerce-a-tale-of-two-technologies

[37]. https://www.youtube.com/watch?v=FH4Zq3i1Qmw

[38]. https://www.youtube.com/watch?v=qYUvCk-G6yk

[39]. https://youtu.be/-2UT2KcnJiE

[40]. https://www.youtube.com/watch?v=2UT2KcnJiE\&feature=youtu.be

[41]. https://www.linkites.com/v-commerce-is-the-nextdigital-transformation-over-e-commerce/

[42]. https://chatbotslife.com/what-is-v-commerce-andwhy-its-ready-to-explode-c4cc6f696e 19

[43]. https://www.hypergridbusiness.com/2015/12/will-vcommerce-replace-e-commerce/

[44]. https://www.linkedin.com/pulse/new-3d-why-vrarv-commerce-tools-alan-smithson/

[45]. https://www.youtube.com/watch?v=-HcKRBKlilg

[46]. https://www.youtube.com/watch?v=IulJN9zFEWs 